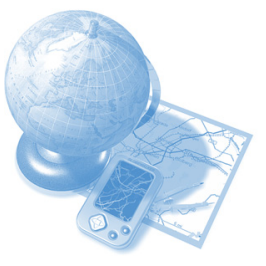

\author{
Christina Mainka \\ Department of Educational \\ Development \\ Napier University \\ Craighouse Rd \\ Edinburgh, EH10 5LG \\ Scotland \\ c.mainka@napier.ac.uk
}

For further information, more examples of online activities or assessment and online discussion grading rubrics please contact the author.

Face-to-face lectures redesigned to incorporate communications technology are valued by students who appreciate the more flexible opportunities for studentstudent, student-tutor communication and peerto-peer support.

\section{Science in the virtual learning environment as more than online conversation}

\begin{abstract}
The asynchronous computer conference still finds itself largely ignored as an effective vehicle for supporting student-centered, collaborative learning experiences. When it is employed the quality of the learning experience varies widely. The literature reports students either unengaged with the medium or overwhelmed by the discussion threads. The online discussion itself tends to take on the nature of an accumulation of independent facts and little peer-to-peer engagement.
\end{abstract}

It is recognised that learning environments in introductory science courses play a crucial role in Higher Education, and dialogic inquiry is understood to play a vital role in the study and understanding of science. According to Biggs " "constructively aligned" learning environments in which careful attention is given to the relationship between learning outcomes, learning activities and teaching practice and assessment strategy are supportive of inquiry.

Based on a series of introductory online physical science modules, designed and taught by the author for the University of Maryland University College (UMUC), it is shown that an aligned virtual learning environment is feasible and supports deep learning. Key factors instrumental to the successful delivery include clear communication of tutor and student role, ample opportunities for social networking and a range of creative learning activities and meaningful assessment tasks. The asynchronous conference plays a central role in which ideas are not only shared but critically examined and improved. Interaction goes far beyond conversation, reaching a deeper level of collaborative inquiry and ultimately knowledge construction ${ }^{2}$.

Science educators are encouraged to incorporate asynchronous conferencing to undergraduate science courses with the aim of fostering collaborative inquiry and critical thinking skills. The case study demonstrates that if the above described features are realised in the online design, the asynchronous conference by default becomes the showplace for knowledge construction from the outset and increasingly the students' major learning resource ${ }^{3}$.

\section{Summary}

The asynchronous discussion tool provided by a virtual learning environment (VLE) is an effective vehicle for supporting student-centred, collaborative learning experiences. We include here computer, online or asynchronous conferences and also discussion boards or forums. The online contributions, however, often tend to take on the nature of an accumulation of independent facts and demonstrate little if any peer-to-peer engagement. It is suggested that this is due to a range of factors including misconceptions about the role of the tutor, inadequately prepared students, and inappropriate tasks, largely unaligned to learning outcomes.

This case study will demonstrate how the asynchronous conference can be employed in a range of imaginative ways not only to extend lecture or seminar time to support lively, collaborative inquiry in introductory physical science courses, but also to prepare students for laboratory practicals and to encourage peer-to-peer support. Engaged activity on the asynchronous discussion board can contribute to a deeper understanding of the fundamental concepts and relationships that undergraduate science students often struggle with. Thoughtful preparation and careful alignment to the face-to-face lecture activity help secure students' active online participation, under the premise that the tutor is visibly online as well. 


\section{Introduction}

It is recognised that learning environments in introductory science courses play a crucial role in Higher Education, and dialogic inquiry is understood to play a vital role in the study and understanding of science. According to Biggs ${ }^{1}$

"constructively aligned" learning environments in which careful attention is given to the relationship between learning outcomes, learning activities and teaching practice and assessment strategies are supportive of inquiry. Teaching practice that encourages students to take a deep, rather than a surface approach to learning (as opposed to a surface approach) unleashes higher level cognitive processes that see the student actively engaged in the learning activity rather than passively receiving information.

Based on a series of fully online environmental science modules, designed and taught by the author, it has been previously shown that an aligned virtual learning environment is feasible and supports deep learning ${ }^{4}$. Key factors instrumental to the successful delivery include clear communication of tutor and student roles, ample opportunities for social networking and a range of creative learning activities and meaningful assessment tasks. In this the asynchronous conference plays a central role in which ideas are not only shared but critically examined and refined. Interaction goes far beyond conversation, reaching a deeper level of collaborative inquiry and ultimately knowledge construction $^{2,3}$.

The asynchronous conference is a more flexible means of communication that, used to extend the physical sciences lecture or seminar discussion time, provides added opportunity for reflection. It also gives all students, in particular the reticent and the non-native English speakers, a more equal footing. Despite widespread belief otherwise, students are often lacking the required technical and communication skills. By paying careful attention to these, the asynchronous conference is employed to enhance the lecture, becoming the showplace for engaging, collaborative scientific inquiry. In the light of the recent emphasis on active learning and on a constructivist approach to science education in order to improve understanding ${ }^{5}$, embedding the asynchronous discussion board into existing teaching strategies can provide a means of meeting a more learner-centred approach to teaching.

\section{Description \\ Case Study}

All the teaching and learning activities described here have been created and supported by the author over the course of 5 years for a fully online undergraduate physical science module, which served as an introduction to the basic principles of physics, chemistry, astronomy, and geology. Students studied the relationships among the physical sciences and the role each of these sciences plays in interpreting the natural world. There was no content placed online beyond a topic-related weekly introduction. The online module was activity and communications driven, knowledge construction largely taking place collaboratively in the asynchronous discussion board. All tasks and quotes presented here represent actual events on the discussion boards over the course of one semester.

The majority of tasks had originally been developed to support the author's face-to-face physical science or inorganic chemistry lectures in a so-called 'blended' delivery mode, the basis for the recommendations in this paper. Slightly modified, the tasks were found to lend themselves equally well to support students on fully online modules. Both modes enjoyed a lively online participation rate in which an average of $85 \%$ of the students engaged with the online activities. In most instances it was found that the level of inquiry and understanding was positively influenced by activities carried out on the asynchronous discussion board.

\section{Uses of the asynchronous discussion to support face-to-face teaching} Education research has found that the standard lecture can be an ineffective way to actively engage students with the lesson material, students often not reaching deeper levels of understanding ${ }^{1}$. (Employing a variety of learning modes recognises the different ways in which students learn and promotes a more stimulating learning experience). The asynchronous discussion tool of virtual learning environments (VLEs), for example, used to support the face-to-face lecture and seminar, can serve to create an active and collaborative online learning environment ${ }^{6}$. Examples that will be introduced in this paper include:

1. Directly linking an online task to enhance lecture activity

2. Extending time for collaborative learning, enquiry, and debate

3. Facilitating a theme-related problem solving forum

4. Supporting group work activities

5. Supporting simple 'kitchen chemistry' tasks. 


\section{Preparation}

The key to the success of the online discussion as a supplementary venue for any of the uses in the above list is its thoughtful preparation. Any attempts at discussion or debate later on will be thwarted if students have not first had the opportunity to familiarise themselves with the VLE, the discussion tool and the nature of online communication. The degree of comfort students feel about learning online plays a key role for the success of any online tool, but this is particularly the case for communications tools. Students often feel inhibited to contribute online for fear of appearing less knowledgeable than their peers, especially given that the written record of the discussion is usually permanently available to the whole class for the duration of the term.

Key strategies for preparing and nurturing a trusting learning environment that are borne out by the learning and teaching experiences in the case study are listed below.

\section{Be there:}

Before even considering to include online communications technology to support your teaching, be sure that you have the time to provide online support, guidance and prompt (within $24 \mathrm{hr}$ ) feedback. Merely creating a discussion board online and announcing its arrival to students in the lecture as an additional area to, 'Go and discuss' will not encourage anyone to use it.

\section{Box 1: Examples of questions that worked}

Topic: Newton's Laws of motion

"Suppose you are standing on the ice of a frozen lake and there is no friction whatsoever. How do you get you off the ice?"

\section{Topic: Free fall}

"Imagine an air resistance-free world. A raindrop formed in a cloud at an altitude of $4000 \mathrm{~m}$. Estimate the speed at which it would hit your head in freefall."

Topic: Fluid mechanics

Sitting next to you on your transatlantic flight to Lisbon, a little girl exclaims, "Cool, it's magic, my gummy bear packet is inflating!" You the studious physical science student (and of little pedagogic skill) disillusion her with a simple scientific explanation. Which one?

\section{Give it meaning:}

In your module guide or syllabus make it very clear from the outset that you will be using the online discussion tool to support your face-to-face teaching. Emphasise the purpose of the online discussion and explain clearly the role of the technology, the role of the student and the role of the tutor. For example, consider awarding grades for online participation based on the quality of the contributions. For an example of an effective method adopted by the author ${ }^{7}$ to manage students expectations, go to 'Myths about taking online classes' at http://polaris.umuc.edu/de/ezine/features/ jan_feb_2004/demyths.htm (Note, that this was aimed at the fully online students, however many elements apply to the blended approach as well.)

\section{Box 2: Students online activity}

Students enjoyed the questions and often matched the fun. Each of the questions listed stimulated a flurry of online activity, questions and exchange between students. Student posts included remarks such as,

"OK, I am beyond confusion now and need some help with this equation!"

"I don't know, but I hope someone can tell me."

"Classmates...in need of some serious help and direction here."

which often prompted other students to help out creating a dialogue of collaborative inquiry often beginning with remarks such as:

"At first, I completely agreed with Thomas, but...."

"I see it your way, Jan....."

"Michael, believe me you are not the only one confused here. I think the answer..."

Appeals directed at the tutor included,

"Christina, am I even close?"

"I honestly have no idea how you keep those equations straight."

By going online, over the course of one week students and tutor were given more time than otherwise available to collaboratively reflect on and solve a wide range of problems in a supportive and trusting learning environment.

3. Give it constructive alignment:

By carefully aligning online communication tasks to face-toface lessons, students recognise the purpose and meaning of both and are more inclined to participate. For example, the results of an online inquiry that informs the subsequent lecture will see more students actively engaged with it than otherwise the case.

\section{Give it rules:}

Fruitful online communication and learning depend on a common understanding of an encouraging written tone and mutual tolerance and respect. Post Netiquette (online etiquette) guidelines and remind students to adhere to them. Limit the word count of posts to allow for equal opportunities of response. Be a role model to the above. Limit the length of time for which the discussion board is available in order to facilitate a rich and focused exchange of thoughts and ideas.

\section{Give it time:}

Long before the online discussion activity is to take place it is recommended that a discussion area is prepared to allow students to become accustomed to the discussion tool and to one another, online. An introductory discussion activity related only loosely to the module materials has been shown to set the right tone from the very start. A question like, "Can you give an example in which a myth or legend has been proposed to explain a natural phenomenon" is one that most students can contribute to, requiring little prior physical science knowledge yet linked to the subject under study. 
Challenge students to guess the number of water molecules in a snowflake or send them to the Scientific Method quiz at http://antoine.frostburg.edu/chem/senese/101/intro/ for example, and then post their results in the online discussion area. Be there to demonstrate interest and concern.

\section{Give it a surprise:}

Give students a reason to login other than just to pass the course. If science is fun, then why not demonstrate that? During a lesson about the natural elements, share with unsuspecting students links to the Periodic Table of Comic Books (at http://www.uky.edu/Projects/Chemcomics/), weave in some science trivia such as Christmas goose thermodynamics, for example, or engage them with the reflex tester (at http://www.happyhub.com/network/reflex/) easily linked to a physics lesson on reaction time. Simple things, like placing a thoughtful quote from a famous scientists (such as "Pick a flower on Earth and you move the farthest star." from Paul Dirac) in a dry lesson on Newton's Universal Law of Gravitation, can go a long way.

\section{Examples of uses of the asynchronous discussion to support teaching}

The underlying design goals for the majority of the tasks described below was to excite students for physical science and to encourage critical thinking skills. By instilling in students a sense that physical science is fun, exciting and relevant to their daily lives, they become more motivated and active in their learning and are more likely to continue their studies.

Stimulating activities that are relevant to the learners interests, and tap into existing knowledge, enhance the learning experience. This approach to teaching is not only central to the constructivist perspective, but lends itself particularly well to the online learning and teaching environment. Online activities that are directly aligned to the lectures give participation in both added relevance and purpose. Face-to-face lectures redesigned to incorporate communications technology are valued by students who appreciate the more flexible opportunities for student-student, student-tutor communication and peer-to-peer support. Advantages for the lecturer include better use of time in the classroom (improved 'time on task'), flexibility of teaching, improved student-tutor communication, and global outreach.

\section{Directly linking an online task to enhance lecture activity} Example: Atmospheric chemistry lesson

The NASA (National Aeronautics and Space Administration) website at http://www.nasa.gov/home/ provides a huge range of educational resources, one of which is the Total Ozone Mapping Spectrometer (TOMS) website at http:// toms.gsfc.nasa.gov/ozone/ozone_v8.html. In a face-to-face lecture on stratospheric ozone, the tutor assigns students each a country above which to retrieve the ozone layer thickness using the online resource, Ozone Overhead, at http://toms.gsfc.nasa.gov/teacher/ozone_overhead_v8.html. For large lectures $(n>100)$ it is recommended to assign countries to groups of students. Students publish their data online (eg, in the VLE) which forms the basis for a moderated online discussion after comparing and evaluating figures for thickness within the context of the face-to-face lesson. The activity is easily taken further by assigning students (or student groups) to monitor and chart their region's ozone layer thickness for a number of weeks comparing this to last year's
NASA data, for example, and making predictions for the future. Students have access to spectroscopic data, from wherever they can go online which might be at the institution, their place of work or at home.

\section{Box 3: Tutor online activity}

The main challenge for the undergraduate science tutor is how to spark initial interest and then encourage, prompt and build confidence in order to maintain that interest. Online, the logoff button is never far away! Equally important for a problems based learning environment described above, is to make it so 'safe' to make mistakes that students recognise making mistakes a natural part of their (deep) learning. This is a particularly precarious undertaking online in a subject area such as physics for a chemistry major, for example, but more so worthwhile given the lack of skill students entering HE have and the minimum timeframe lecturers struggle to fit their curriculum into.

In the physical science context of fundamental principles, concepts and theorems it becomes the online tutor's responsibility to monitor online activity and step in and gently correct where necessary, always maintaining an encouraging tone.

For example, to address a misunderstanding the class has:

"Well, you all have demonstrated a good understanding of Boyle's Law, but what about forgetting to deflate the tires of a bike stored in the (unpressurised) belly of a plane.....?"

Or to encourage one student to rethink a response or calculation:

"Hmmm, careful-do remember that for free fall the equation is............ Would you try it again? Anyone else willing to help us out?"

"James, thanks for trying! Now let me ask you, in your calculation for the kinetic energy, what did you use for v?"

The website enriches the core textbook and lecture by visually demonstrating the concepts under discussion. NASA also makes available an online textbook, Stratospheric Ozone (http://www.ccpo.odu.edu/SEES/ozone/oz_class.htm). Learners are offered a combination of visual and interactive elements that enable them to better grasp the basics of ozone layer depletion. In addition the learner takes an active role in learning by engaging in research related tasks such as data gathering and analysis, problem solving and authentic enquiry.

\section{Extending time for collaborative learning, inquiry, and} debate

Carefully chosen web resources and relevant websites broaden the range of information available to the student and can easily convey a sense of interrelatedness between the sciences, encouraging students to make new connections on their own as well. Employing online communication tools extends the time available for critical discussion and debate, creating engaging experiences for collaborative learning that might otherwise not be realised in the setting of traditional teaching. 
In the following example, a geology lesson goes beyond exploring the formation of rocks or the chemical composition of minerals, by tapping into environmental science issues to which the students can directly relate and explore in the online discussion board.

Example: Geology lesson

In a geology seminar students are prompted to consider factors contributing to the depletion of natural resources. The ensuing debate is subsequently carried out online in the asynchronous discussion board over the period of the following two weeks.

The nature of the question is crucial for stimulating online discussion. Open-ended questions that spark interest and controversy work well, for example. In the case study the following question proved very successful: "Population growth is said to be at the root cause of resource depletion. Consider the proposal by an industrialised western nation to make foreign aid conditional upon the stopping of population growth by the poor, overpopulated recipient nations".

Students were directed to visit two websites (Facing the Future, at http://

www.facingthefuture.org/, and Population Studies, at http:// www.pop.org/ ) that clearly support opposing views, which formed the basis for critical class discussion, first face-to-face and then online. They were also encouraged to draw from additional hard copy or online resources at their disposal. This online activity supports conceptual learning, objective analysis, collaborative learning, and collective decision making.

3. Facilitating a theme-related problems solving forum

For students struggling with

fundamental concepts in

physical science or mathematics the asynchronous conference can offer a flexible and collaborative means of support. Online, students can reflect longer about problems as well as draw from each other, rather than solely from the tutor, to assist their understanding. By posing imaginative, probing questions that encourage students to think about principles and concepts outside of the classroom, students apply rather than repeat knowledge and become engaged in lively exchange (see boxes 1: 'Examples of questions that worked', 2: 'Students online activity' and 3: 'Tutor online activity').

\section{Supporting group work activities}

The use of case studies teaches physical science to students within a 'real' life context. Case studies relate course material to real world scenarios the student can identify with and lend themselves particularly well to online learning by putting the student at the centre of the learning process. Within the context of a group work assignment, students are prompted to find solution pathways in collaboration with other students, and by making use of a variety of resources. This could be lecture material, readings from the core text, websites or e-books.

When presented as a case study, the asynchronous conference can serve as the students' area for collaborative online group discussion adding flexibility to group tasks otherwise constrained by the time and place for all group members to meet face-to-face. The asynchronous conference can be used in combination with the synchronous chat and could be linked to a collaborative working space, such as a wiki. Group projects can be published online for viewing by all, and a class discussion board then serves as the showplace for peer review and class debate, for example.
The biggest online databank of science related case studies free to use by all practitioners is the University of New York at Buffalo's Case Studies in Science $^{8}$ repository at http:// ublib.buffalo.edu/libraries/ projects/cases/ ubcase.htm\#pharm/. The JISC supported Resource Discovery Network (RDN) also maintains a small collection of case studies at http://www.rdn.ac.uk/ casestudies/.

\section{Supporting simple 'kitchen} chemistry' tasks

Practicals designed so that the only materials required can be found in a household, can also be useful to illustrate selected principles of physical science. Hands on experiments introduce the scientific method and its practical application to science as well as to everyday questions and problems. A typical activity might include preparing a homemade $\mathrm{pH}$ indicator from red cabbage juice, etching a series of metals $(\mathrm{Cu}, \mathrm{Zn}, \mathrm{Al}, \mathrm{Fe})$ with a salt-vinegar solution or a felt tip pen chromatography experiment carried out on coffee filter paper with a variety of readily available household solvents.

Each laboratory description is posted in the asynchronous discussion board together with any online resources such as the interactive periodic table website (at http:// www.chemicalelements.com/ ), helpful simulations, or 3-D models. Students are encouraged to share experiences of collecting material, designing the experiment and recording any observations online. In the interest of promoting problem solving skills a move away from the 'cookbook' instruction format is recommended, clearly formulating the learning objectives instead and leaving it to the students to identify and collect materials and to design the experiment. Students have proved themselves most resourceful (in one instance using a cigarette carton as a measuring device) and regularly share apparatus and observations by uploading digital images and video clips for the rest of the class to see online. 


\section{Additional uses}

1. Preparing students for face-to-face laboratory classes Creating an online discussion board in which experimental procedures, pitfalls and safety concerns are reviewed beforehand saves valuable laboratory time (and glassware). Students are better prepared for laboratory activity after engaging with safety and procedural related questions posted online, which they can solve together supported by a teaching assistant, for example. Virtual chemistry laboratory safety tutorials are also available from UK web resources such as the national electronic repository, Education Media OnLine (EMOL) which has recently become Film \& Sound Online (http://www.filmandsound.ac.uk/)

\section{Questions forum}

The creation of an online questions forum for any course related questions (eg, timetable, assignments), together with a clear 'private inquiries only' email policy stems email inbox traffic markedly. After a few courses, compiling an online FAQ list reduces all inquiries even further. It is crucial here that response time is kept to a minimum.

\section{Socialisation space}

In large lectures especially, students tend to remain either anonymous or locked into smaller peer groups. By making an informal online socialisation space available students have the opportunity to communicate with all class members at their own convenience. Students recommend books and movies to one another as well as exchange good and bad learning experiences, which can result in a supportive network of learners. Clearly indicate that this is a non-moderated online discussion area.

\section{Starting small}

As shown above, the asynchronous conference can be used in a wide variety of ways to support the physical science lecture: nevertheless, it is recommended to start 'small'. Consider maintaining a discussion board as a questions forum in the first instance, in order to familiarise yourself with discussion threading and online communication. Invite students to share a science web resource or two with the class on a discussion board. Visit the sites and return comments to the contributor, which acknowledges the student's online efforts and gives you the opportunity to practice posting. There is no need to embed the asynchronous conference into your teaching until you feel comfortable and confident enough to do so, which will also ensure that your students have a positive and rewarding online learning experience.

\section{Conclusion}

Science educators are encouraged to incorporate asynchronous conferencing imaginatively into undergraduate science courses as a meaningful and flexible supplement to the face-to-face lecture. By doing so it has been shown that collaborative inquiry and critical thinking skills are supported, which ultimately contribute to the students' enthusiasm for the physical sciences. The case study demonstrates that if prepared thoughtfully, the asynchronous conference can be instrumental in actively engaging students with the material and supporting a deep understanding of the concepts and principles of physical science.

\section{References:}

1. Biggs, J., Teaching for quality learning at university, Berkshire: SRHE and Open Univ. Press (2003)

2. Scardamalia, M., Collective cognitive responsibility for the advancement of knowledge (2002). In Smith, B. (Ed.), Liberal education in a knowledge society (pp.209-248) Mahwah, NJ: Lawrence Erlbaum Associates

3. Van Aalst, J., Rethinking the nature of online work in asynchronous learning networks, BJET 37, 2, 279-288 (2006)

4. Brown, N., Smyth, K. and Mainka, C., Looking for evidence of deep learning in constructively aligned online discussions (2006). In Banks, S., Hodgson V., Jones, C., Kemp B., McConnell, D. and Smith C. (Eds), Proceedings of the Fifth International Conference on Networked Learning (2006). Lancaster: Lancaster University

5. Hake, R. R., Interactive-engagement versus traditional methods: A six thousand-student survey of mechanics test data for introductory physics courses, American Journal of Physics 66, 1, 64-74 (1998)

6. Chickering, A. W., Ehrmann, S. C., Implementing the Seven Principles, AAHE Bulletin, pp 3-6 (1996, October). Available online at the Teaching, Learning and Technology Group (TLT) website (http://www.tltgroup.org/ programs/seven.html)

7. Harding, G., Mainka, C., Myths about taking online classes, DE Oracle@UMUC (2004). Available at http:// polaris.umuc.edu/de/ezine/features/jan feb 2004/ demyths.htm

8. University of New York at Buffalo, Case Studies in Science (2006). Available online at http:// ublib.buffalo.edu/libraries/projects/cases/ ubcase.htm\#pharm 